\title{
Enhanced recovery after surgery pathways in thoracic surgery, do they end at discharge?
}

\author{
Maria Rodriguez, Maria Aymerich \\ Clinica Universidad de Navarra, Madrid, Spain \\ Correspondence to: Maria Rodriguez. Clínica Universidad de Navarra, C/Marquesado de Santa Marta 1, 28027, Madrid. Email: mroperez@unav.es. \\ Provenance: This is an invited article commissioned by the Editorial Office, Annals of Translational Medicine.
}

Submitted Aug 20, 2019. Accepted for publication Sep 07, 2019.

doi: $10.21037 /$ atm.2019.09.59

View this article at: http://dx.doi.org/10.21037/atm.2019.09.59

Fast track pulmonary resection protocols have shown to be feasible and to improve hospital related costs, shortening length of stay and maintaining quality of care (1-4).

Despite the increasing number of scientific literature addressing the benefits of specific lobectomy pathways $(4,5)$ and the recent publication of Enhanced Recovery after Surgery $\left(\right.$ ERAS $\left.^{\circledR}\right)$ guidelines in thoracic surgery (4-6) the truth is that the description of most of these interventions ends at patients' discharge, with no clear indications for follow up or measures to prevent unintended hospital readmissions $(2,3)$ (Table 1$)$.

Hospital readmissions have been traditionally included as both, an outcome and a quality indicator after lung resection $(7,8)$ but there is scarce thoracic surgery-focused literature with measures to prevent them. Furthermore, unexpected hospital readmissions are not only related with an increased short and long-term mortality risk but also with important economic implications (9-11).

In some series, readmission rates in the first 30 days after lung resection are as high as $6 \%(7,9,12)$ whereas they go up until $19 \%$ in the first 90 days $(8,13)$. Furthermore, the most frequent diagnosis for readmission in the first 30 days are postoperative complications (13). These data suggest the implementation of an evidence-based follow up protocol to prevent emergent hospital readmissions or unnecessary consultations becomes mandatory, especially in the era of ERAS ${ }^{\circledR}$, where maximum quality of care is attempted reducing hospital stay and costs $(6,14)$.

Colorectal cancer surgery has been one of the pioneering specialties not only in ERAS ${ }^{\circledR}$ guidelines implementation but also in the development of measures to decrease postoperative readmission rates (15).

Halverson et al. (15) in an attempt to identify process measures to reduce unintended postoperative readmissions after bowel resection, highlighted the importance of nutrition, continuity of care, physical therapy, transfer of information to the patient and to the referral physician and follow up in the delivery of high-quality care and in the reduction of postoperative readmissions.

Whether or not these measures will be valid if extrapolated to lung resection still remains unknown. It is even unclear if thoracic surgeons should follow lung cancer resection patients after their hospital discharge $(16,17)$ and some authors have proven it increases costs without necessarily detecting more recurrences or improving longterm survival $(16,17)$. What seems necessary is to establish an efficient communication between the surgeon who has operated on the patient and the primary care or referring physician who is going to follow him. This communication should assure the continuity of care necessary to detect and treat early postoperative complications if they appear and to give the patients the necessary information and support to go through the expected postoperative recovery successfully $(7,15)$.

Although it may sound paradoxical, the successful discharge process should start preoperatively, with the appropriate evaluation of the risk-factors, comorbidities and expected postoperative support of the patient $(6,18)$ in order to prevent possible complications or adverse events delaying hospital discharge. Information given beforehand to both, the patient and the referral physician can help them design the best suitable follow up plan for the postoperative period (18).

Keeping the patient and the referral physician updated 
Table 1 Summary of interventions addressed in Thoracic Surgery ERAS $^{\circledR}$ guidelines [Adapted from Batchelor et al. (6)]

Preoperative phase
Preadmission information, education and counselling
Smoking cessation

Anaemia management

Alcohol dependency management

Pulmonary rehabilitation and prehabilitation

Preoperative fasting and carbohydrate treatment

Preanaesthetic medication

Perioperative phase

Venous thromboembolism prophylaxis

Antibiotic prophylaxis and skin preparation

Preventing intraoperative hypothermia

Standard anaesthetic protocol

PONV control

Regional anaesthesia and pain relief

Perioperative fluid management

Atrial fibrillation prevention

Surgical technique: thoracotomy

Surgical technique: minimally invasive surgery

Postoperative phase

Chest drain management

Urinary drainage

Early mobilization and adjuncts to physiotherapy

PONV, postoperative nausea and vomiting.

on the recovery along the whole postoperative period reinforces their engagement and decreases unplanned postoperative readmissions $(5,15)$. Furthermore, providing the patient and the referral physician with common alert signs after lung resection can improve postoperative recovery and outcomes, even in patients submitted to thoracotomy $(4-6,19,20)$. Among the information to be provided are symptoms and signs of both, systemic and local infection, and early detection of deep venous thromboembolism symptoms. It's important to encourage patients to consult, either to the responsible surgeon (21) or to the primary care physician (17), when they notice fever higher than $38^{\circ}$, surgical site infection, changes in the quality and quantity of sputum (specially in chronic obstructive disease patients) and changes in the cardiac rhythm or the baseline shortness of breath (7). Instructions and information about basic nutritional recommendations (1,500 kcal diet) and expected recovery (limits of pain, expected exercise exertion, normal woundhealing process) should also be included in the discharge summary as well as an efficient method for communication. Telephone communication has proven to be a suitable alternative for verbal transmission of information $(20,22,23)$ and what is more important, it seems an appropriate follow up alternative for thoracic surgeons (17). However, the most efficient schedule or adequate intervals for this follow up have not been validated in the literature. A call $48 \mathrm{~h}$ after discharge, a week and a month later seem the most spread and appropriate schema $(5,21-23)$ but further evidence of its utility is lacking. The need for presential follow up has to be clarified and standardized too (15). This should assure appropriate healing of the wounds and assessment of nutritional status, daily-activities independence, unplanned consultation for surgery-related causes and adequate oncological treatment if needed $(15,24)$. Postoperative follow up dates should be preferably arranged in advance, to increase patient's adherence and decrease system related errors $(18,25)$.

Finally, making sure the patient, their families and the referral physician understand all the information and agree with it is another important, although sometimes missed, step in order to improve postoperative recovery $(5,18)$.

There is no doubt ERAS $^{\circledR}$ and fast-track pathways after thoracic surgery have opened a wide range of possibilities, highlighting again, the importance of perioperative care and information in the optimization of results after thoracic interventions. However, most of the recommendations included in these protocols have not been validated in large populations and most of them have been extrapolated from other surgical specialties. If they improve short and long term outcomes after lung resection or decrease the incidence of unplanned readmissions still needs to be investigated, but to ours, appropriate transition of care among the three phases of the perioperative period is something that needs to be encouraged and emphasized, especially at the processes level, assuring efficient reciprocal communication, adequate recovery and improvement of quality after lung resection (Table 2). 
Table 2 Summary of pre-discharge and post-discharge interventions as well as those facilitating transition of care [Adapted from Hansen et al. (10)]

\begin{tabular}{|c|c|c|}
\hline Pre-discharge interventions & Post-discharge interventions & Interventions facilitating transitions between phases \\
\hline $\begin{array}{l}\text { Medication reconciliation (With clear } \\
\text { instructions regarding anti-platelet and } \\
\text { anticoagulation medication as well as newly } \\
\text { introduced medication) }\end{array}$ & $\begin{array}{l}\text { Telephone follow up after discharge } \\
48 \mathrm{~h} \\
1 \text { week } \\
1 \text { month }\end{array}$ & $\begin{array}{l}\text { Continuity of care assurance (either by surgeon, } \\
\text { primary care or referring physician) }\end{array}$ \\
\hline $\begin{array}{l}\text { Follow up appointments organized at discharge } \\
\text { Primary care or referral physician } \\
\text { Surgeon } \\
\text { Oncologist if needed }\end{array}$ & $\begin{array}{l}\text { Direct communication method } \\
\text { (phone, email, pager) facilitated to } \\
\text { patient and family }\end{array}$ & \\
\hline
\end{tabular}

\section{Acknowledgments}

None.

\section{Footnote}

Conflicts of Interest: The authors have no conflicts of interest to declare.

Ethical Statement: The authors are accountable for all aspects of the work in ensuring that questions related to the accuracy or integrity of any part of the work are appropriately investigated and resolved.

\section{References}

1. Wright CD, Wain JC, Grillo HC, et al. Pulmonary lobectomy patient care pathway: a model to control cost and maintain quality. Ann Thorac Surg 1997;64:299-302.

2. Cerfolio RJ, Pickens A, Bass C, et al. Fast-tracking pulmonary resections. J Thorac Cardiovasc Surg 2001;122:318-24.

3. McKenna RJ Jr, Mahtabifard A, Pickens A, et al. Fasttracking after video-assisted thoracoscopic surgery lobectomy, segmentectomy, and pneumonectomy. Ann Thorac Surg 2007;84:1663-7; discussion 1667-8.

4. Brunelli A, Thomas C, Dinesh P,et al. Enhanced recovery pathway versus standard care in patients undergoing videoassisted thoracoscopic lobectomy. J Thorac Cardiovasc Surg 2017;154:2084-90.
5. Madani A, Fiore JF Jr, Wang Y, et al. An enhanced recovery pathway reduces duration of stay and complications after open pulmonary lobectomy. Surgery 2015;158:899-908; discussion 908-10.

6. Batchelor TJP, Rasburn NJ, Abdelnour-Berchtold E, et al. Guidelines for enhanced recovery after lung surgery: recommendations of the Enhanced Recovery After Surgery (ERAS $\left.{ }^{\circledR}\right)$ Society and the European Society of Thoracic Surgeons (ESTS). Eur J Cardiothorac Surg 2019;55:91-115.

7. Varela G, Aranda JL, Jimenez MF, et al. Emergency hospital readmission after major lung resection: prevalence and related variables. Eur J Cardiothorac Surg 2004;26:494-7.

8. Handy JR Jr, Child AI, Grunkemeier GL, et al. Hospital readmission after pulmonary resection: prevalence, patterns, and predisposing characteristics. Ann Thorac Surg 2001;72:1855-9; discussion 1859-60.

9. Puri V, Patel AP, Crabtree TD, et al. Unexpected readmission after lung cancer surgery: A benign event? J Thorac Cardiovasc Surg 2015;150:1496-1504, 1505.e1-5; discussion 1504-5.

10. Hansen LO, Young RS, Hinami K, et al. Interventions to Reduce 30-Day Rehospitalization: A Systematic Review. Ann Intern Med 2011;155:520-8.

11. Freeman RK, Dilts JR, Ascioti AJ, et al. A comparison of length of stay, readmission rate, and facility reimbursement after lobectomy of the lung. Ann Thorac Surg 2013;96:1740-5; discussion 1745-6. 
12. Hu Y, McMurry TL, Isbell JM, et al. Readmission after lung cancer resection is associated with a 6-fold increase in 90-day postoperative mortality. J Thorac Cardiovasc Surg 2014;148:2261-7.e1.

13. Jean RA, Chiu AS, Hoag JR, et al. Identifying Drivers of Multiple Readmissions After Pulmonary Lobectomy. Ann Thorac Surg 2019;107:947-53.

14. Stowers MDJ, Lemanu DP, Hill AG. Health economics in Enhanced Recovery After Surgery programs. Can J Anesth 2015;62:219-30.

15. Halverson AL, Sellers MM, Bilimoria KY, et al. Identification of process measures to reduce postoperative readmission. J Gastrointest Surg 2014;18:1407-15.

16. Gilbert S, Reid KR, Lam MY, et al. Who should follow up lung cancer patients after operation? Ann Thorac Surg 2000;69:1696-700.

17. Varela G, Jiménez M, Hernández-Mezquita M. [Followup of patients with non-small-cell pulmonary cancer undergoing complete resection. Should surgeons be in charge?]. Arch Bronconeumol 1998;34:14-6.

18. Refai M, Andolfi M, Gentili P, et al. Enhanced recovery after thoracic surgery: patient information and care-plans. J Thorac Dis 2018;10:S512-6.

Cite this article as: Rodriguez $M$, Aymerich M. Enhanced recovery after surgery pathways in thoracic surgery, do they end at discharge? Ann Transl Med 2019;7(Suppl 8):S357. doi: 10.21037/atm.2019.09.59
19. Jack BW, Chetty VK, Anthony D, et al. A reengineered hospital discharge program to decrease rehospitalization: a randomized trial. Ann Intern Med 2009;150:178-87.

20. Hess DR, Tokarczyk A, O'Malley M, et al. The Value of Adding a Verbal Report to Written Handoffs on Early Readmission Following Prolonged Respiratory Failure. Chest 2010;138:1475-9.

21. Scarci M, Solli P, Bedetti B. Enhanced recovery pathway for thoracic surgery in the UK. J Thorac Dis 2016;8:S78-83.

22. Bostrom J, Caldwell J, McGuire K, et al. Telephone follow-up after discharge from the hospital: does it make a difference? Appl Nurs Res 1996;9:47-52.

23. Dudas V, Bookwalter T, Kerr KM, Pantilat SZ. The impact of follow-up telephone calls to patients after hospitalization. Am J Med 2001;111:26S-30S.

24. Chen YY, Huang TW, Chang H, Lee SC. Optimal delivery of follow-up care following pulmonary lobectomy for lung cancer. Lung Cancer (Auckl) 2016;7:29-34.

25. Hernandez AF, Greiner MA, Fonarow GC, et al. Relationship Between Early Physician Follow-up and 30-Day Readmission Among Medicare Beneficiaries Hospitalized for Heart Failure. JAMA 2010;303:1716-22. 